\title{
SHARING ECONOMY: SEEING THROUGH THE FOG
}

\author{
Daniel TRABUCCHI \\ Politecnico di Milano \\ School of Management \\ Via Lambruschini 4B \\ 20156 Milano (MI) \\ Italy \\ daniel.trabucchi@polimi.it \\ +390223993947
}

\author{
Laurent MUZELLEC* \\ Trinity College Dublin \\ Trinity Business School \\ College Green \\ Dublin 2 \\ Ireland
}

laurent.muzellec@tcd.ie +35318964299

\author{
Sébastien RONTEAU \\ Audencia Business School \\ 8 Route de la Jonelière - BP31222 \\ 44312 Nantes cedex 3 \\ France \\ sronteau@audencia.com \\ +33 (0)2.40.37.46.21
}

This is a post-print version of the paper published on the Internet Research: Daniel Trabucchi, Laurent Muzellec and Sebastien Ronteau, (2019) "Sharing Economy: Seeing through the fog", Internet Research, https://doi.org/10.1108/INTR-03-2018-0113

Emerald allows authors to deposit their AAM under the Creative Commons Attribution Non-commercial International Licence 4.0 (CC BY-NC 4.0). To do this, the deposit must clearly state that the AAM is deposited under this licence and that any reuse is allowed in accordance with the terms outlined by the licence. To reuse the AAM for commercial purposes, permission should be sought by contacting permissions@emeraldinsight.com.

For the sake of clarity, commercial usage would be considered as, but not limited to:

- $\quad$ Copying or downloading AAMs for further distribution for a fee;

- Any use of the AAM in conjunction with advertising;

- $\quad$ Any use of the AAM by for promotional purposes by for-profit organisations;

- Any use that would confer monetary reward, commercial gain or commercial exploitation. 


\begin{abstract}
Purpose: The purpose of this paper is to delineate the current state of the art of Sharing Economy research and practice. It provides a new framework to help managers and academics to consider this field with the right managerial and theoretical lenses.

Design/Methodology/Approach: A systematic literature on the sharing economy was conducted, resulting in the analysis of 114 articles in the management literature. This was completed by the empirical investigations of business model and industry of 32 members of three national associations promoting sharing economy: Sharing Economy UK, Ireland, and Denmark.

Findings: Papers dealing with SE themes focus on consumers' motivations, impact on the society, market, and policy, as well as the revenue model. SE businesses can be differentiated depending on whether their assets are new or re-used and the transaction is permanent or temporary. Based on this matrix, our study reveals four archetypes of sharing economy businesses: "On-Demand renters", "Lifecycle extenders", "Seller aggregators" and "Ephemeral matchmakers".
\end{abstract}

Research limitation/implications: The paper outlines a significant gap between what is the current focus of the academic literature and the reality of sharing economy purposes and businesses. This provides goals for future research.

Practical implications: The framework and clustering of business model archetypes may help managers and entrepreneurs dealing with sharing economy to better understand the underlying value drivers behind those business models.

Originality/Value: There are some discrepancies between the SE themes emerging from the management literature and the business model diversity of SE companies. This research aims at helping scholars and managers to position themselves in the field.

\title{
KEYWORDS
}

Sharing economy; digital platforms; marketplaces; two-sided markets; systematic literature review; business model

\section{Introduction}

The Sharing Economy (SE) has significantly challenged well-established industries, such as the transport and hotel industry, by providing low-cost convenience without the responsibility of ownership (Eckhardt and Bardhi, 2015). The phenomenon seems to be worldwide and growing rapidly. In Europe, the total value of transactions undertaken by SE companies is estimated at $€ 28$ billion for 2015 and is expected to reach $€ 335$ billion by 2025 (PwC, 2016). The growth rate of these businesses significantly outperforms their traditional counterparts. The Compound Annual Growth Rate for car rental is for example estimated at $2 \%$ through 2025, while for car sharing, estimation rose to 34,8\% from 2016 to 2024 (PwC, 2014). It is expected that the US adults using SE should move from 44.8 million in 2016 to more than 86.5 
million in 2021 (Statista, 2017a) or from 7.7 million in 2014 to 19.3 million when considering only the lodging platforms (Statista, 2017b).

Those differences in the growth estimation can be attributed to uncertainties about what exactly is to be included in the SE. The term is mainly used to describe an economic and social activity for which, as a core process, we find transactions related to sharing and/or reusing assets. However, several definitions focus on different elements of the phenomenon (e.g. Habibi et al., 2017; Kathan et al., 2016). Sometimes stressing the need of a digital platform (e.g. Mair and Reischauer, 2017; Acquier et al., 2017); sometimes emphasizing on the reciprocity of the phenomenon in others: "The act and process of distributing what is ours to others for their use and/or the act and process of receiving or taking something from others for our use" (Belk, 2017, p.126). Other definitions focus on the impact regarding sustainability (Botsman and Rogers, 2011) and/or social value (Belk, 2009; Benkler, 2017).

Recent works show how four SE models can be identified depending on the level of rivalry amongst participants and the level of control exerted by the platform owns (Constantiou et al., 2017). The same authors also contend that SE platforms possess three key attributes that distinguishes them from other businesses: they provide access rather than ownership, they facilitate peer-to-peer interactions, they allocate idle resources (Constantiou et al., 2017). This only partially corroborate the views of Munoz and Cohen, (2017) who showed the diversity of SE purposes: peer-to-peer interaction, better use of under-used resources, or leverage the crowd to find alternative funding sources. Furthermore, the role of business model design is often considered a critical variable for the economic sustainability of these models, independently from the motivations that bring the customers on board (Piscicelli et al., 2018). Similarly, other research classifies SE initiative through nine different sharing practices, stressing the interdisciplinary nature of the topic (Trenz et al., 2018). At the same time, other authors are taking a different perspective, paying attention to the individual level of the SE, studying the motivations behind the participation (Lee et al., 2018).

This brief overview shows a complex environment. Different definitions, with different focuses, coming from the academic world and the real world where a bunch of companies claims themselves part of the SE phenomenon, often without matching (many) of those definitions. This illustrates that there is some confusion about the scope of SE and key characteristics of the businesses involved in it. A fog is blanketing the Sharing Economy concept.

We aim to delineate the theoretical boundaries of this new research topic, and observe the key characteristics of SE companies; their business model configuration and their key attributes. The aim is not necessary to provide another definition of the concept but rather to provide academics and practitioners with a map and a compass that will help them to respectively shape their research agenda and their business agenda.

To delineate the scope of this new research topic, we propose a dual approach based on a systematic literature review and an empirical investigation of members of three sharing economy industry associations. This dual approach enables us to identify gaps in the literature and cluster the different kinds of SE companies, pointing out related opportunities and 
challenges for managers, entrepreneurs, and start-uppers dealing with this growing phenomenon. The paper is organized as such. First, we explain our systematic literature review approach and the methodology used for the empirical investigation. We then present a thematic analysis of the literature and cluster the various business models used by sharing economy companies claiming. Implications for both researchers and managers are exposed towards the end of the paper.

\section{Methodology}

The present study is based on a dual systematic approach based on mixed methods. The first part of the research is based on a systematic literature review with a specific focus on research related to SE. Systematic literature review uses an explicit algorithm to perform a search and critical appraisal of the literature (Tranfield et al., 2003; Crossan and Apaydin, 2010). The second part of the research is based on exploratory qualitative research of sharing economy companies, using an open coding approach (Jansen, 2010).

\subsection{Defining the samples}

\subsubsection{The sample for the Systematic literature review}

Systematic literature review benefits from a long tradition in management fields (Tranfield et al., 2003; Pittaway et al., 2004; Liñán and Fayolle, 2015; Qazi et al., 2017). The ambition of a Systematic literature review is 'to provide practitioners and policy-makers with a reliable basis to formulate decisions and take actions by enhancing the legitimacy and authority of the resultant evidence' (Tranfield et al., 2003, p.208).

In opposition to descriptive and narrative reviews, systematic literature reviews 'uses an explicit algorithm, as opposed to a heuristic, to perform a search and critical appraisal of the literature. Systematic reviews improve the quality of the review process and outcome by employing a transparent and reproducible procedure (Tranfield et al., 2003; Crossan and Apaydin, 2010).

To understand what the academic world considers under the term "Sharing Economy", our search strategy exclusively focuses on the keyword "Sharing Economy". The search was performed in the field "Article, Abstract and Keywords" of the Scopus database, the largest citation database of peer-reviewed literature. This aimed to keep the initial sample as wide as possible but also to include only results of good quality, as ensured by this kind of database (e.g., Randhawa et al., 2016). The search was performed on all the papers published till the end of 2017. This first step brought to 671 documents. To ensure the coherence between the documents and the aim of this paper, the search has been then limited to the subject area "Business, Management and Accounting", reducing the dataset to 230 papers. The next selection criteria were based on the document's type which only included "Articles" and "Articles in press" excluding a further 75 documents (such as conference proceedings). The last exclusion criterion was the language, keeping only documents in English (resulting in 146 documents). Finally, the abstracts were screened to ensure consistency with the aim of this research, resulting in a final sample of 114 documents. The steps of the literature search are summarized in Figure 1. 


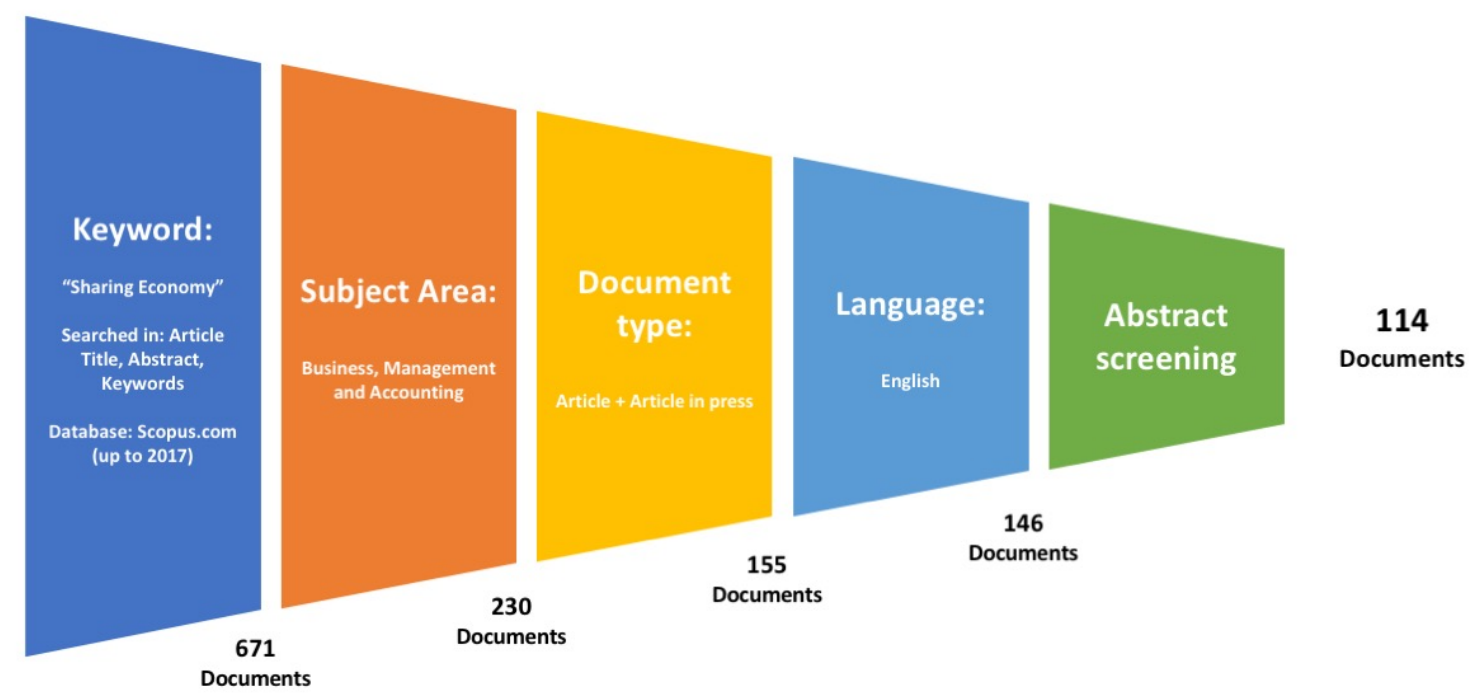

Figure 1 - Creation of the final sample of papers

\subsubsection{The sample for the empirical analysis}

To analyze SE from an empirical perspective, we searched for associations that bring together companies involved in this growing phenomenon just as for the systematic literature review, we focused exclusively on associations that had the term "sharing economy" in their title. Sharing Economy Ireland, Denmark, and the UK are three non-profit industry associations, which bring together key players of the SE in their respective industry. There was no other European association that contained the word "sharing Economy". The search of associations stopped to Europe, as we reached a sample which was big enough for the aim of our research and a number of players (including US based companies such as Uber, Airbnb) were reoccurring in the different associations, albeit it is worth noting that many companies have initially originated from the US. The three industry associations have similar objectives. For example, Sharing Economy Ireland aims to "bring together diverse technology-enabled businesses offering unique ways of generating economic, social and environmental value across a range of peer to peer, business to business, and business to consumer models operating throughout Ireland". The original sample of the three industry associations included 45 companies. Members providing additional services for SE businesses (e.g., law consultancy, payment management), which cannot be considered as part of the SE phenomenon were excluded from the sample leaving a final dataset of 32 companies.

\subsection{Data analysis}

The 114 articles, constituting the research dataset, have been analyzed according to the suggestions of systematic literature reviews (Tranfield et al., 2003; Crossan and Apaydin, 2010). The dataset is first described in details (time of publication, key authors, and key journals) then an overview of the emerging theme of the literature are presented.

Regarding the empirical analyses, the 32 companies have been studied through secondary sources (e.g., websites, description of their mobile apps on the app stores, industry magazine, newspaper articles), aiming to have an overall view on the companies and the entire sample. 
All the gathered data have later been analyzed, following an open coding approach (Corbin and Strauss, 2008).

Based on insights derived through both the analyses, directions for future research and implications for managers and entrepreneurs are presented.

\section{Results}

\subsection{Systematic literature review}

The dataset 114 articles were first analyzed through some descriptive statistics, as it is common in systematic literature reviews (e.g., Qazi et al., 2017; Alcaide-Muñoz and Rodriguez Bolívar, 2015). Thematic analysis of the papers follows it.

\subsubsection{Sharing Economy: An emerging and growing academic field.}

Our analysis of the database confirms the incredible growth of the field over the last few years. The oldest paper on the sharing economy was published in 2012. The academic interest for the topic is new but is now growing at exponential rates with seven papers published in 2015, 29 papers in 2016 and 76 in 2017 (Figure 2).

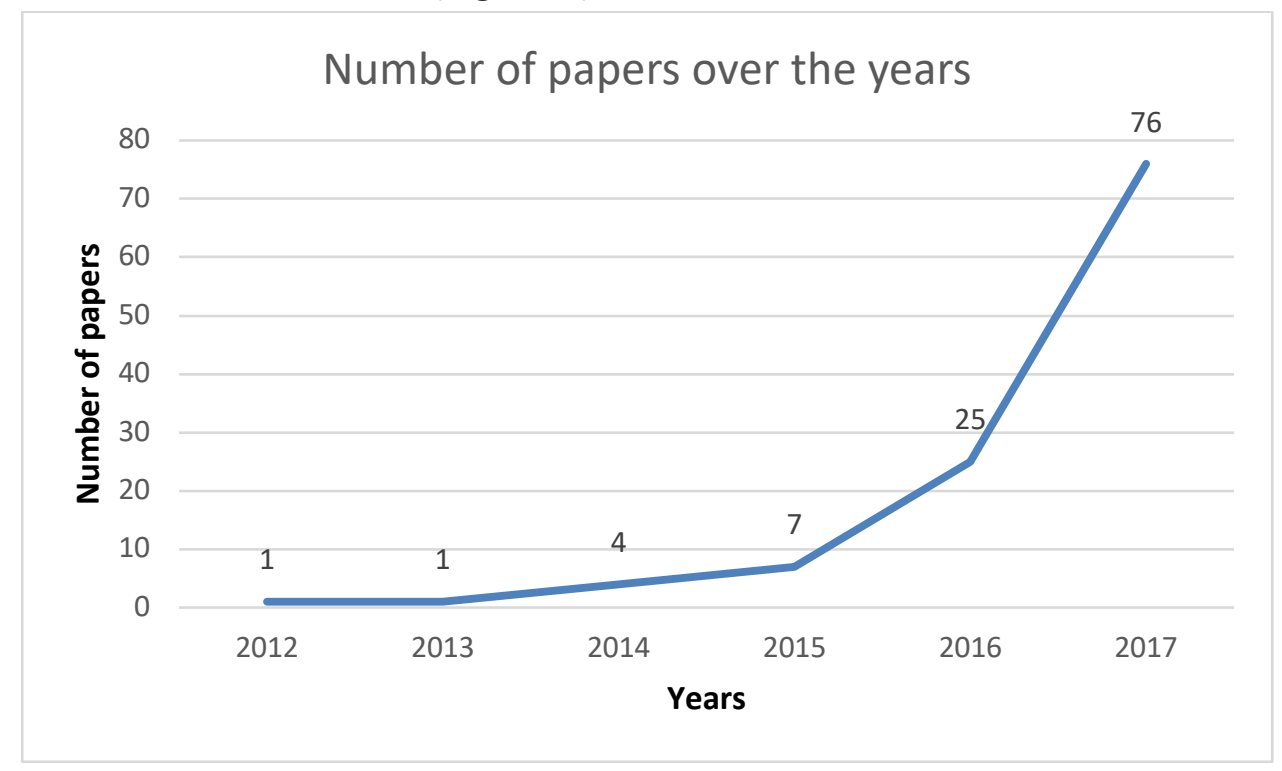

Figure 2 - Number of papers per year

Those papers were written by a great variety of authors showing that no authors are setting a school of thoughts. Only 10 authors in total had published more than one paper on the topic: seven of them had published two papers while the three most prolific authors (Xie, Cohen, and Tussyadiah) had published respectively five and three papers.

The journal landscape analysis also reveals a great heterogeneity (Figure 3). Thirteen academic journals featured at least three articles on the sharing economy. Two of those journals had recently published more than 10 papers: "International Journal of Contemporary Hospitality Management"- and "Technological Forecasting and Social Change"; in these cases, it is important to highlight that both journals published a special issue on the topic. 


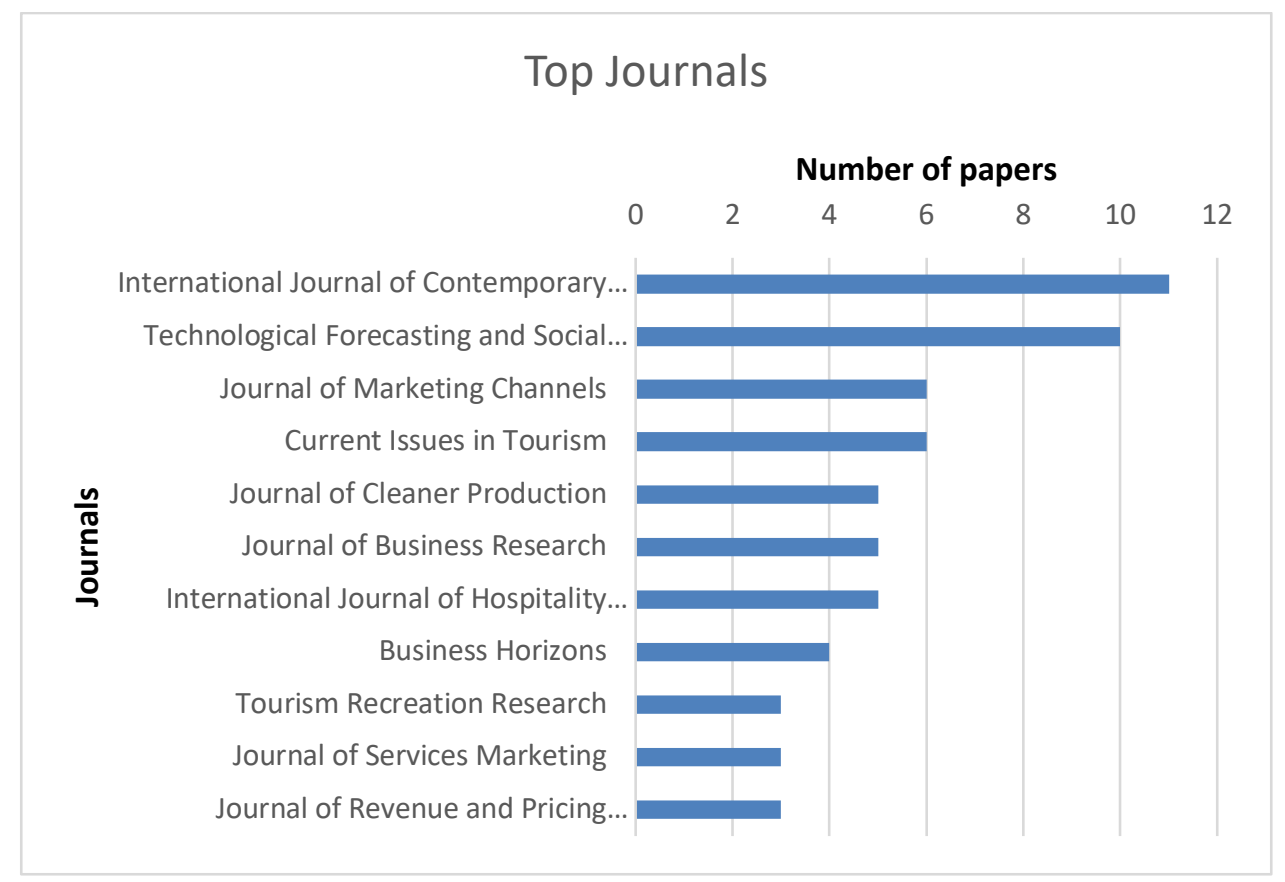

Figure 3-Top journals represented in the sample

\subsubsection{Thematic analysis: What are the scholars talking about?}

To analyze the content of the sharing economy academic papers, we first perform a networkbased analysis on the co-occurrence of both authors' keywords and the index keywords via VOS Viewer, a bibliometric analysis software.

This resulted in a co-occurrence map (Van Eck and Waltman, 2014). To increase the readability of the results, links are showed only for a minimum strength higher than 6 .

Based on a smart local moving algorithm (for further information, see Waltman and Van Eck, 2013), Figure 4 shows the results of a cluster analysis of related keywords (Waltman et al. 2010), representing each cluster with a different color.

A few insights derived from the co-occurrence analysis. First of all, the relative importance to the tourism sector emerged through its leading case (Airbnb), showed by the red cluster. The blue and yellow keywords are mainly related to behavioral economics and a sustainability dimensions, through keywords like sustainability, access based consumption, sustainable development or collaborative economy. The third type of related keywords (in orange and green) are management oriented, through terms like business model, innovation, economics, commerce and the trust issue. These dimensions also emerged from the qualitative analyses of the papers. 


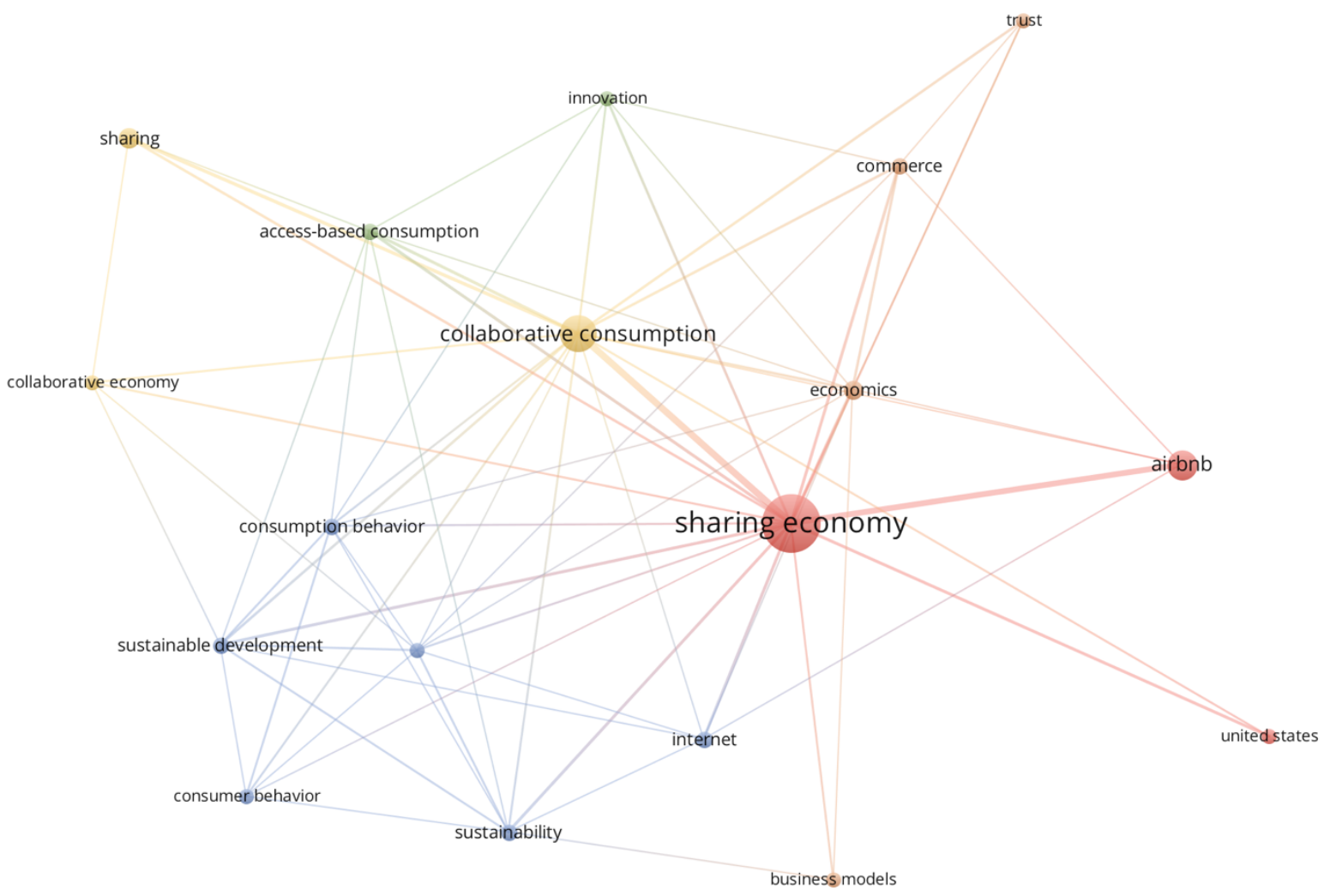

Figure 4-Cluster analysis on co-occurrence of keyword

Our qualitative clustering analysis reveals themes, which can be classified in 3 groups: consumers' motivation for joining the SE, impact on the society, market and policy, and finally revenue model of the SE (Figure 5), one last group is composed of papers that try to define the SE (as mentioned in the Introduction).

\section{Main focus of the paper}

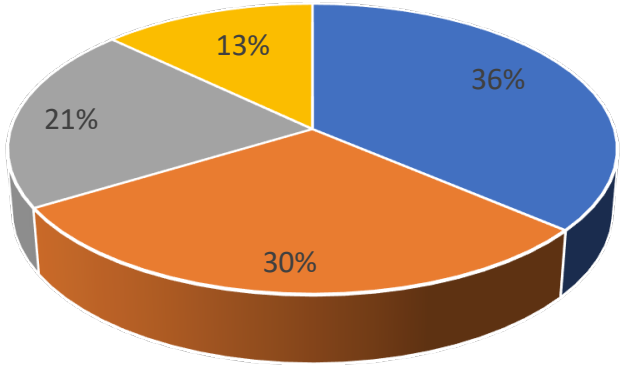

- Consumers' motivations

- Impact on the society, market and policy

- Business Model and Revenue model

- Definition or frameworks

Figure 5-Main focus of the papers in the sample 
The greatest number of papers on SE focuses on the drivers, that motivate customers in using the services provided by these companies, taking a user-centric perspective (e.g., Wilhelms et al., 2017). The literature outlines three motivations: financial benefits (e.g., Milanova and Maas, 2017), hedonic considerations (e.g., Yang et al., 2017), and finally environmental consciousness or sustainability orientation (Parguel et al., 2017). Research also shows that those behavioral motivations may be industry-specific or culturally-dependent (Davidson et al., 2018). For example, the sustainability orientation argument is more prevalent for peer-topeer based businesses (Parguel et al., 2017).

The second type of topics emerging from the literature relates to the potential impact of the $\mathrm{SE}$, which can be seen from 3 dimensions: environment, market, and policy. The environmental dimension embraces the notion of sustainability. SE is described as a way to reduce unused products, and waste (Barnes and Mattsson, 2016; Retamal, 2017). Researchers further suggest exploring the potential impact of new technologies to improve even more the sustainability role of SE practices (Heylighen, 2017). Beyond the sustainability benefit and impact of the SE on society, researchers also highlight the market impact of the emerging share economy business. Here, research shows how an increase in the offer of share goods may lead to an increase in the overall demand (Guttentag and Smith, 2017) and how existing, traditional companies may search for new ways to leverage their brands, instead of simply competing with SE (Richard and Cleveland, 2016).

Several papers also outline the unsolved policy issues (e.g., taxation, regulation, human resources policies) posed by SE firms (Laurell and Sandström, 2017). SE challenges the traditional forms of public regulations (Gregory and Halff, 2017). The need to control and define new and improved metrics in the field is often highlighted (e.g. Williams and Horodnic, 2017).

The final theme has a managerial focus and relates to revenue model and pricing mechanisms. In SE, price discrimination can be related to the owners' characteristics (Wang and Nicolau, 2017) and SE companies have different revenue streams (Richard et al., 2018). Most interestingly, Laurell and Sandström (2017) highlighted how the sharing economy field embraces market and non-market logic, since not all the SE businesses can be considered for profit organization.

The diversity of topics uncovered in academic papers contrasts with the limited number of industries under investigation (Figure 6). Most papers focus on the accommodation industry (34\%) and use Airbnb as a prime example. The second biggest category includes papers covering multiple industries (approximately 25\%). 10\% of the papers are not based on an empirical investigation and are purely conceptual. 


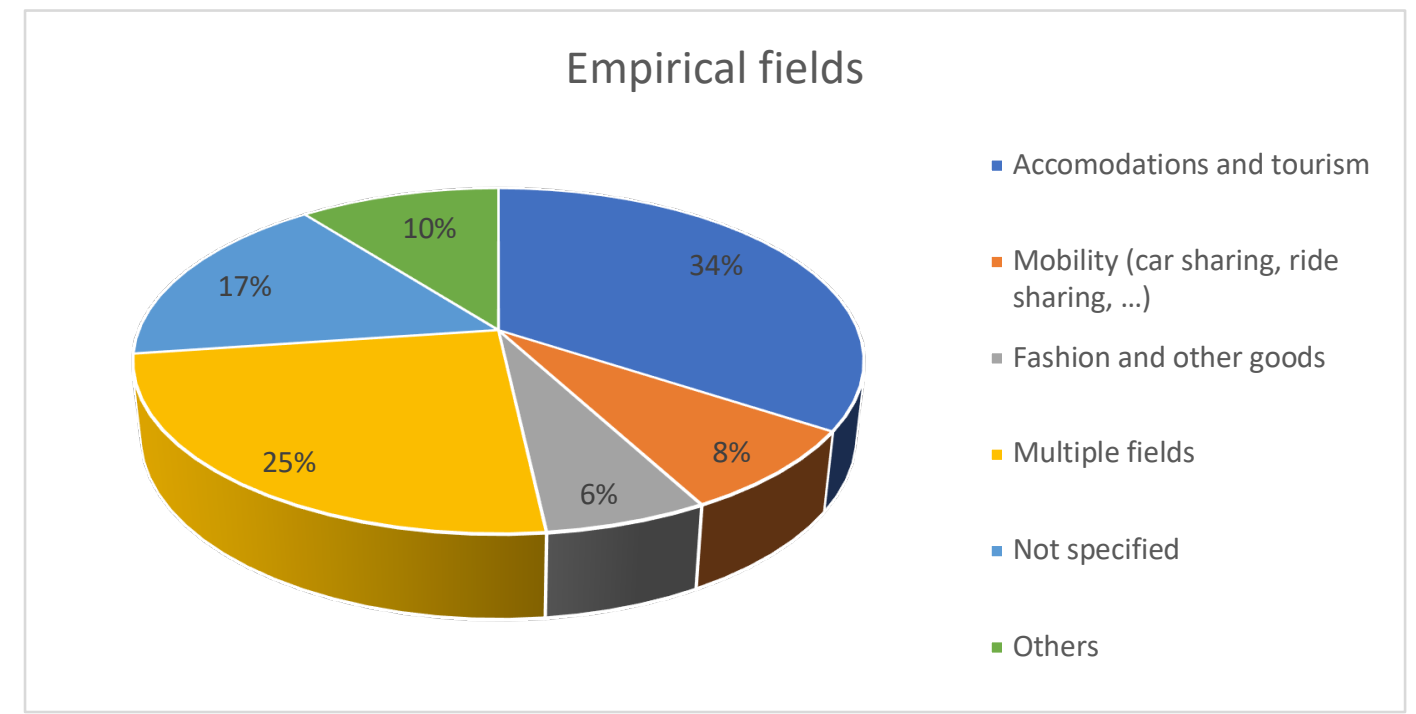

Figure 6 - Empirical fields covered in the papers

Albeit insightful, the systematic literature review conducted above only offers a very partial view of what SE truly is. Specifically, the limited number of cases and industries under investigation by academics may not be representative of the vast array of businesses and industries of SE. Therefore, to provide a more definitive overview of the SE phenomenon, it is useful to look at companies involved in SE and analyze more their industry and business models.

\subsection{Who Is Taking Part in the Sharing Economy}

Our empirical investigation shows that the members of sharing economy Ireland, UK and Denmark operate mainly in the mobility sector (28\%), accommodation industry (22\%), retail (16\%); while other sectors (e.g., food, fashion, energy) are only represented in small proportion. The sample of 32 companies is further analyzed along three dimensions: i) the object of the sharing process, ii) the kind of transaction enabled by the company and iii) the business model adopted by the company.

\subsubsection{What do SE companies actually share?}

The first level of analysis is related to the "shared object": What are SE companies actually sharing? The results of a high-level analysis are quite surprising; the vast majority of companies are intermediating physical goods (cars, clothes, homes), while the others are sharing workforce (Figure 7). 


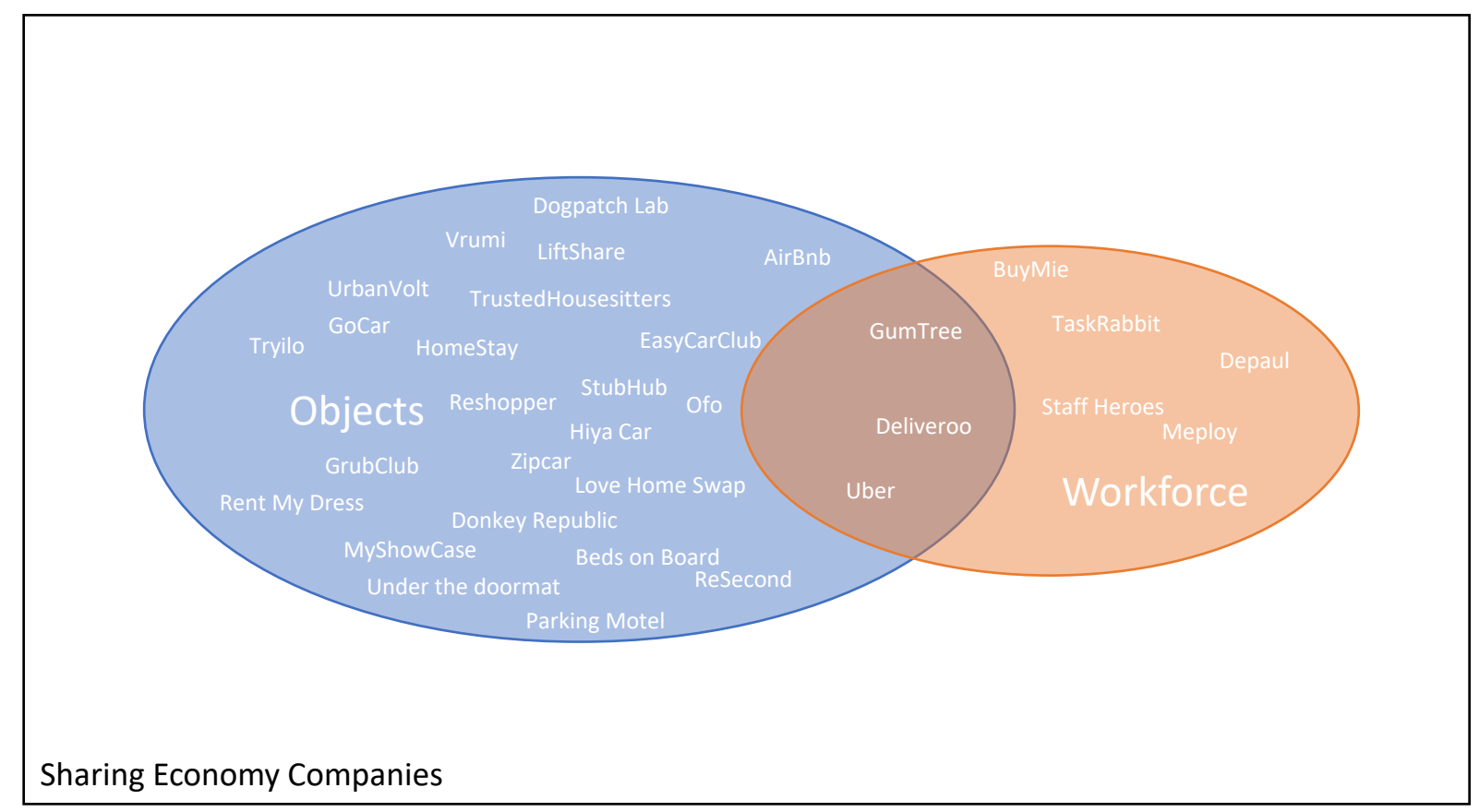

Figure 7 - Sharing economy companies: The object of the sharing

The first category comprises peer-to-peer platforms like Airbnb, which enable on a shared consumption model where "access trumps ownership" such as Ofo or GoCar that respectively share bikes and cars. The second category is made up of job matching companies, such as Staff Heroes, which allow businesses to search for extra staff or the Danish Meploy that "matchmakes" companies and people searching for flexible jobs. In the middle, hybrid companies can be found, leveraging a flexible workforce to trade a physical good. Deliveroo, which links customers and restaurants through their drivers, is a prime example of this hybrid position. This initial analysis shows the great variety of sharing objects, which can be referred to SE. Indeed, the so-called "gig economy"-defined as "a labor market characterized by the prevalence of short-term contracts or freelance work, as opposed to permanent jobs" (Wilson, 2017)-is represented in the sample. The gig economy emerges as a subset of businesses, considering a spread workforce and the chance to provide flexible jobs. As there is a huge level of heterogeneity among the shared objects for this initial level of analysis, it is necessary to refine our analysis with the next level of analysis focusing on the kind of transaction enabled by the company to get further insights.

\subsubsection{What kind of transactions is enabled?}

Concentrating on physical goods, the second level of analysis focuses on the temporality of the transaction and the newness of the asset, used in this transaction.

Some companies such as Vrumi, Airbnb or Love Home Swap embody the SE concept as they leverage on an existing asset-an empty room, a vacant apartment and so on-to engage users in a temporary transaction.

Other companies incarnate the concept of sharing within their industry such as car sharing, but are often based on a completely different model. In this case, the company owns the shared product, which has been bought ad hoc for the sharing purposes. 
Still, another set of companies perform on a model where they extend the lifecycle and economic value of used goods. Reshopper, for example, is a platform where people can sell and buy used children's items.

Accordingly, our analysis reveals a 2 by 2 matrix based on two main dimensions: the kind of asset involved in the sharing and the kind of transaction enabled by the company (Figure 8).

Temporality of the transaction

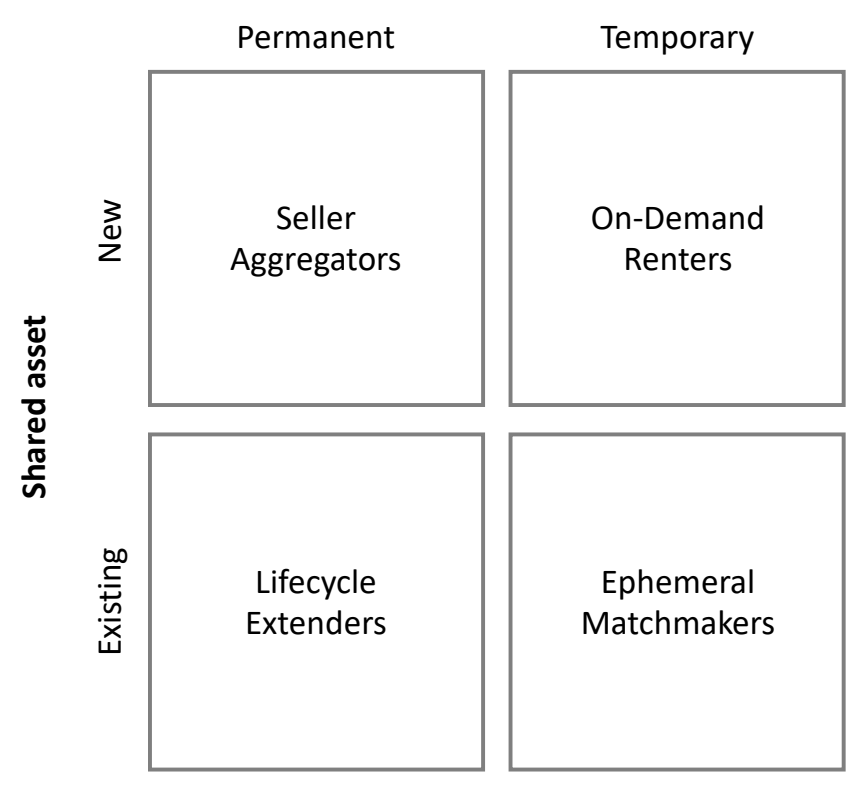

Figure 8 - A Framework to read SE

This classification brings to the emergence of 4 main clusters of SE companies labeled as Seller Aggregators, On-demand Renters, Lifecycle Extenders and Ephemeral Matchmakers.

Lifecycle Extenders and Seller Aggregators involve a change of ownership. Those businesses are in fact marketplaces, which enable a sale of new or used products. MyShowCase is an online beauty store, which sells new brands not widely available on high street shops through community-based events organized by a network of independent stylists. BuyMie is a retail grocery application, which allows users to have home deliveries (within an hour) from close brick and mortar groceries using an independent workforce known as "pickers". Reshopper allows users to re-sell used clothes, while StubHub helps users to re-sell exceeding tickets for events.

Temporary transactions comprise On-demand Renters and Ephemeral Matchmakers. Ephemeral Matchmakers facilitate an exchange between two types of users with symmetric needs, i.e., providing an object and consuming an object. Airbnb exemplifies this category. Similarly, Tryilo is an Irish start-up, which allows people to rent out rarely used objects-such as a kayak or a professional camera - to other users in the same city. They, however, focus on experience rather than ownership, hence the name "Ephemeral Matchmakers". On-demand Renters allow users to have access to a good, which has been intentionally purchased for this purpose. Ofo allows users "rent" bikes on-demand rent around the city, or GoCar, rents out shared cars. 


\subsubsection{Who owns what?}

Accounting for the (initial) owner of the shared object reveals some interesting considerations. On the one hand, several companies act as intermediaries bringing together prospective customers searching for specific products and on the other, owners of the desired good.

This mechanism has been widely studied in the last decade through the concept of two-sided markets. Scholars defined them as markets where two or more groups of customers are brought together through a platform, which internalizes the indirect network externalities governing the relationship between the two groups (e.g., Rochet and Tirole, 2003; Muzellec et al., 2015). Successful companies such as Uber and Airbnb rely on this kind of market structure by linking end-users with a peer-supplier (i.e., drivers or hosts in these examples). Multi-sided platform is also the business model for hybrid companies like Deliveroo (previously classified as an overlapping case between objects and workforce), that brings together three different sides: the end-users, restaurants, and riders (e.g., Hagiu and Wright, 2015). Our analysis reveals that Seller Aggregators, Lifecycle Extenders, Ephemeral Matchmakers are based on this market arrangement.

Finally, if we consider the last cluster-On-demand Renters-we find a different mechanism. Companies like Ofo or GoCar are the actual owners of the shared good. Their business model is based on an innovative version of the traditional renting business model. Indeed, they leverage a digital gate (usually a mobile app) to manage the multiple and on-demand rents offering a direct access to the shared goods, without a human intermediary.

Temporality of the transaction

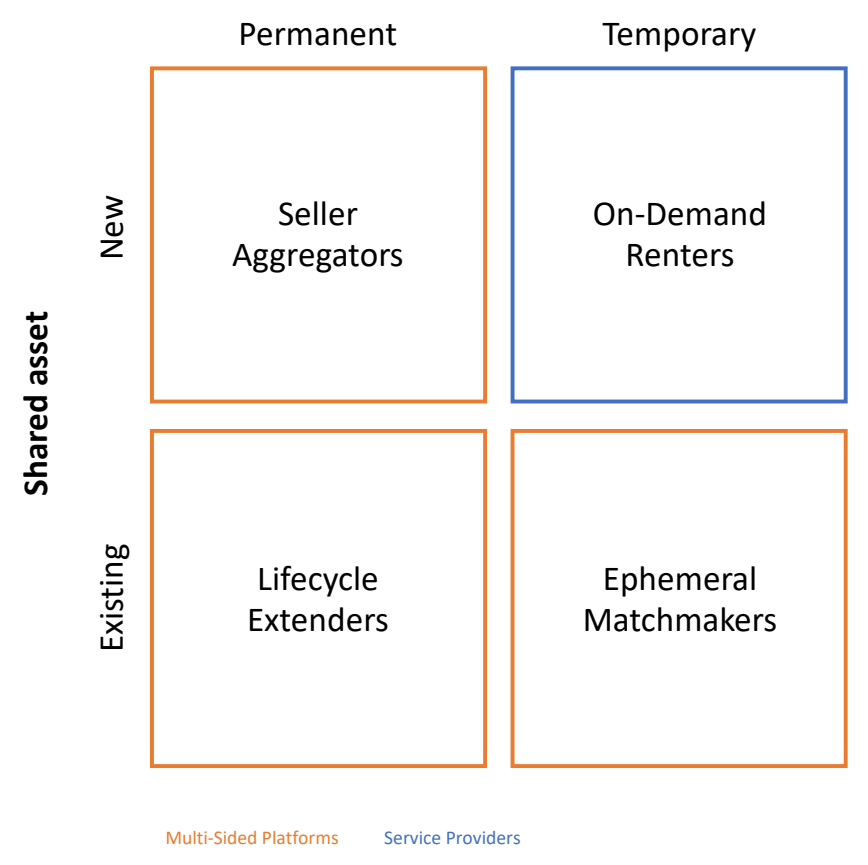

Figure 9-Sharing economy companies: A typology of platforms

This final difference leads to a critical aspect in the definition (and the management implications) of SE companies. If, in several cases, the concept of platform is used as a core 
element for the definition of what is SE (e.g., Mair and Reischauer, 2017; Acquier et al., 2017), it is also true that not all the companies, which leverage the peculiarities of these sociological phenomena are actually based on this kind of business model (Figure 9).

In the next section, the focus is going to be moved to the business model and the strategic implication of these differences, aiming to unveil the opportunities and challenges, which underpin these different business models.

\section{Discussion}

The present framework helps companies to position themselves on the spectrum. It helps SE players to analyze the extent to which it is the changing of ownership features or their use of existing resources, which classifies them as a participant in the SE. More interestingly, it can be used as the basis for a more in-depth discussion to see what drives the success of Business Model archetypes behind Sharing Economy.

\subsection{Ephemeral Matchmakers}

Ephemeral Matchmakers, defined as companies, which enable a temporary transaction of existing assets, represent the majority of the sample (approximately 66\%) and their modus operandi is probably the closest to what is commonly understood as SE.

Companies like Airbnb and HomeStay, along with platforms that assist in finding a flexible job, like Staff Heroes are part of this group. Indeed, these multi-sided platforms often leverage idle capacities, valuing existing-but under-used-assets. These companies are satisfying a need, which may already be partially satisfied by incumbents.

The companies of this cluster may be labeled as two-sided markets or two-sided platforms (Hagiu and Wright, 2015), which refers to a specific kind of platform that aims to link two different groups of customers (Rochet and Tirole, 2003; Gawer, 2014) relying on cross-side network externalities (Katz and Shapiro, 1985; Shapiro and Varian, 1999). Hence, entrepreneurs should pay attention to the design of two specific value propositions, which touch the right motivation drivers for each side. SE matchmaking platforms present the same challenges as other multi-sided platforms. In particular, attention should be given to the chicken and egg paradox (Caillaud and Jullien, 2003), and the opportunities of managing platforms throughout the life cycle (Eisenmann, 2007). The question hence is why should endusers and providers participate in these platforms instead of using a traditional service? Also, how matchmakers' value propositions differ from what traditional firms offer?

As outlined by the systematic literature review, end-users' motivation may be related to the potential financial benefit (e.g. a lower price), but also the hedonic experiences (e.g., Verganti, 2017). The analysis of the value proposition of SE corroborates this perspective. On the endusers' (consumers') side, SE companies tend to put forward the notion of experience (rather than ownership) and authenticity (rather than professionalism). For example, Airbnb's value proposition emphasizes the authenticity of an experience: "book unique homes and experience a city like a local". The idle-capacity dimensions of those platforms can also be related to sustainability motivation argument, albeit the emphasis for the provider side (suppliers-owners working with Airbnb, Vrumi) is leaning towards potential financial gains 
("Vrumi allows householders in the UK to make extra money from renting out their unused space to busy professionals during the day").

The success of those matchmaking platforms will depend on their ability to build trust. Since the platform itself acts as a warranty towards the other side, trust-enabling mechanisms are essential to entice both sides to join the platforms. Our analysis reveals that this is achieved through three key mechanisms: identity verification, user reviews, and secure payment.

Identity verification is the initial trust-building mechanism used by Airbnb, BlaBlaCar and other SE companies, requiring end-users to initially sign up through one and very often two social media platforms (such as Facebook, Google + or LinkedIn).

Once users are signed into the platform, a mechanism must ensure the quality of the service. One-sided rating mechanism (the rating of Uber drivers by taxi users) or more often reciprocal reviewing (i.e., hosts and travelers reviewing each other on Airbnb, HomeStay, Love Home Swap etc.,) is essential to building trust on both sides of the market.

Finally, trust is also built through a secure payment system, which collects money from the end user's side and delays the payment to the provider's side until the transaction is completed and all parties satisfied.

\subsection{Lifecycle Extenders}

Lifecycle Extenders are companies (e.g., Reshopper or ReSecond), which leverage existing assets to create a sale-based transaction; they represent approximately $11 \%$ of the overall sample. Here, the concept of sharing is somehow missing, since the "supplier" group sells something to the "customer" group. However, this cluster partially overlaps with the so-called "circular-economy", in which participants also aim to increase the lifecycle of products (Urbinati et al., 2017). Sustainability can be considered as the main motivational driver for buyers. Sellers are motivated by utilitarian reason (gaining an economic incentive) along with the willingness to promote a more sustainable lifestyle. Hence, managers could put forward the notion of sustainability in their value propositions for both sides of the platform. This is clearly what ReSecond in Denmark is doing with the slogan: "Give before you take it: What have you done to save the planet today?" However, focusing solely on the sustainability element may restrict market size; hence, convenience, proximity or safety may constitute better arguments to entice consumers to join the platforms. In the UK, Reshopper put forward the following value proposition: "Buy and sell used children's items, easily and safely in your own city". Like other multi-sided platforms, success is partially conditioned by the platforms' ability to build trust amongst participants. Secure payment mechanism and truthful ratings system of participants are designed to guarantee a minimum acceptable quality of service.

A similar approach has been previously defined in the literature through the work of Botsman and Rogers (2011), regarding the chance to increase the usage of idle resources and somehow extend the lifecycle of a product. Their view is mainly linked with the chance to increase the usage of products without changing the ownership (i.e., car-pooling) or to the chance to design ex-ante an extended product-service system lifecycle. Nevertheless, in our view 
"Lifecycle extenders" are companies that extend the life of a product by connecting the products' original owners and future consumers of a now used asset.

\subsection{Seller Aggregators}

Seller Aggregators are one of the two smallest clusters in the sample, accounting for approximately $11 \%$ of the sample. These companies are based on a permanent sale transaction for new assets or products; hence, their membership in the sharing economy industry network is surprising. They share with the previous clusters the fact that they are platforms connecting two-sided markets. In the context of SE, those platforms often offer a new way for small firms on the supply side (such as the restaurants in Deliveroo) to reach an extended customer base, while offering the users a unique point of entry to search and order from a variety of small suppliers. These companies may find difficult to define a sustainable pricing mechanism (since they are usually based on transaction fees) and they often need to search for innovative ways to capture the value they created. In this perspective, companies may capture value exploiting the value of the huge amount of data, which they collect on buyers, sellers and the data generated through their interactions (Trabucchi et al., 2017, 2019). The literature on marketplaces (e.g., Viswanathan et al., 2010; Täuscher and Laudien, 2018) may help to understand companies belonging to this cluster.

\subsection{On-Demand Renters}

The last cluster represents $17 \%$ of the sample and shows the greatest heterogeneity. Ondemand Renters are companies, which enable a temporary transaction on new assets. Almost all cars and bikes sharing companies belong to this cluster. Car sharing has been considered for example a resistant innovation (Ram, 1989; Claudy et al., 2015), trying to change the rooted behavior of the customers while offering new opportunities. For this reason, the motivation drivers need once again to be highly-related to the design of the value proposition: Why people should want to participate in these kinds of businesses? In these cases, the sustainability perspective on the SE may play a key role. Indeed, even if the shared assets have been created ad hoc, they are going to be used by multiple user, and eventually they aim to reduce the overall consumption reducing the time where those assets are not used. However, the value propositions, which seem to resonate the most with consumers are focused on convenience, e.g. "Donkey Republic: 24/7 Bike Rental, find a bike near you and unlock with your phone" and user experience, e.g., Zip Car: "Own the trip, not the car: a smarter way to get around the city".

The competitive advantage and key factors of success for those services reside in their ability to master on-demand technology linked to mobile applications including the app's extreme user-friendliness, inventory management, and asset/user geo-localization. On-demand renters are not two-sided platforms; they only have one type of customers, whom they need to convince just like any traditional single-side market. However, their business model has implications for the amount of capital needed to set up such businesses. In the previous categories, the platform could be launched with no capital invested in the shared asset as it 
was provided by a third party (Rifkin, 2014). On the other hand, on-demand renters need a huge amount of capital not only to set up the platforms and attract potential users, but also to buy the assets, which are going to be shared. These companies need to pay attention to very different dynamics, for example the reasons why people may decide to rent instead of to buy (e.g., Knox and Eliashberg, 2009) or different models of governance in non-ownershipbased services (e.g., Ndubisi et al., 2016).

\section{Managerial takeaways: lifting the fog.}

In summary, this research aims to help managers and academics to approach the SE phenomenon with a slightly different perspective. It does so in the following manner. First, the study shows that SE models are not constraints to the accommodation sector, but also concern the automotive/transportation industry, a host of emerging sectors such as job platforms, retailing, restaurants, energy. Our research also shows that SE companies are for the most part digital platforms, which connect two types of users where a provider shares/rents/exchanges a specific asset with a user. We labelled those types of companies' ephemeral matchmakers as they enable the temporary exchange of an asset between two sides of a market. This type of businesses is already well-described in the literature and is typical of the accommodation industry. Our research has helped to extend the boundaries of SE to industries and business types previously ignored by the academic and managerial literature. This study shows that sharing economies also include on-demand rent platforms, which commonly mutualized the use of an asset (e.g., car) so that individual ownership is not necessary. It also extends to companies (Lifecycle Extenders), which allow individuals to buy or resell used items. Not all the companies in SE aim to share; in some cases, they sell, but do not use existing products such as the seller aggregator's category. Therefore, each category requires a different managerial focus.

Ephemeral matchmakers are often two-sided digital platforms which require a careful design of two value propositions matching the needs of each sides. Managers of Lifecycle Extenders Businesses may still rely on that model, but also put forward the sustainable element of their businesses. Entrepreneurs entering the Seller Aggregators category should try to emulate successful marketplace (e.g. Amazon). Here the focal point should be the platform usability, to achieve customer centricity and data harvesting. On-Demand renters may focus their attention on service design and the successful mechanisms of business model based on renting and subscriptions.

Finally, some takeaways also for incumbents and "traditional" companies may be provided. If companies are the providers of a service/product where the change of ownership is not a sine qua non-condition for the customers' experience, then they can be severely exposed to the threat of SE entrants. Considering this, it is hardly surprising that the rental industry is the industry, which has been the most disrupted. Airbnb is renting rooms and apartments just like any other hotels. Here the pain for those incumbent players has been aggravated by the fact that not only a change of ownership is not necessary in the rented accommodation industry, but the customers' experience very often surpasses the experience of renting a hotel room (see Airbnb motto: "Belongs anywhere"). If a company finds itself in a sector where the 
current set of resources can be leveraged by a third party (SE players), it should also consider itself in danger. For example, one member of Sharing Economy Ireland is revolutionizing the grocery retail market. BuyMie is an app, which allows consumers to order their groceries from a supermarket chain of their choice and be delivered within an hour. Contrary to most ecommerce websites, the start-up has not invested in expensive delivery system and warehousing solutions; it just focuses on the app usability and references existing products of the incumbent brick and mortar retail chain. Buymie leverages the retail network of incumbent players, seeing each retail outlet as a warehouse/delivery hub. Once the user has done his shopping list on his/her mobile phone, a "picker" can go shopping on the buyer's behalf in the most conveniently located shop and deliver it within an hour. In the process, Buymie collects a huge amount of data on the shopping habits of hundreds of consumers across several shops. However, traditional retailers could react and leverage their current proximity with consumers by building a platform, which would connect people who cannot and don't want to go shopping with consumers shopping in their shops, so that through the mediation of an app, some shoppers would deliver groceries to sedentary clients.

\section{Limitations and Future Research}

\subsection{Limitations}

This paper started with a simple observation: there are a number of definitions highlighting different attributes of Sharing Economy businesses (e.g., Habibi et al., 2017; Kathan et al., 2016; Mair and Reischauer, 2017; Acquier et al., 2017; Belk, 2007; Botsman and Rogers, 2011; Constantiou et al., 2017; Munoz and Cohen, 2017; Piscicelli et al., 2018) and the same time there are some companies claiming to be part of $\mathrm{SE}$, that do not necessarily possess those attributes. It is a qualitative research with some limitations regarding the sample size and the lack of primary resources. Our paper does aim to provide statistically significant results regarding the analyzed categories but instead it simply aims to clear the fog surrounding this new phenomenon. To do so, we do not provide a new definition, that may end up being too wide or too narrow. We simply provided lenses to scholars and managers to help them see through the fog.

\subsection{Future Research Avenues}

This research shows a misalignment between the ongoing literature streams regarding the SE phenomenon and the diversity of companies taking part in it.

For example, we showed how most previous researches in the field are focused on the accommodation industry, which represents a key pillar of the entire SE, but it is not the only one. The academic community also needs to look at the Sharing Economy potentials and implications for retailers, restaurants, car manufacturers, office provider, and so on.

Regarding the topics studied so far, the landscape is wider, but still quite polarized. Indeed, almost three papers out of four considered in our review consider the customers' standpoints (i.e. through motivations and, behaviors) or the incumbents' perspective (i.e. Impact on the 
market, policy implications). A relatively small number of papers have just started to focus on the business models behind the SE companies, mainly studying the pricing dynamics. Yet, Sharing Economy companies are redefining markets and industries to an extent rarely seen before. It is essential to understand the drivers of SE companies' success.

Our study suggests that more research needs to be undertaken from the company standpoint. What does it mean to design the value proposition of a SE company? How can entrepreneurs develop such businesses? What are the critical success factors that differentiate those companies? How do SE companies reach the critical mass? How do they overcome the chicken and egg paradox? What are the diffusion of innovations patterns of SE company? Do they differ from their traditional counterparts?

Academic research in the field has grown at a fast rate in recent years. A significant percentage of those papers try to define what is and what is not part of the phenomenon. At the same time, the empirical world is moving at a different pace, and the next step should be moving on, from the definition of the phenomenon to the study of these companies. Our framework is a small initial step in this direction. Academics should consider the four different types of sharing economy companies across multiple sectors. Our study reveals that the two or multisided platform literature constitutes very appropriate lenses to focus on ephemeral match makers and life-cycle extenders SE companies.

\section{REFERENCES}

Acquier, A., Daudigeos, T. and Pinkse, J. (2017), "Promises and paradoxes of the sharing economy: An organizing framework", Technological Forecasting and Social Change, Vol. 125, pp. 1-10.

Alcaide-Muñoz, L. and Rodríguez Bolívar, M.P. (2015), "Understanding e-government research: A perspective from the information and library science field of knowledge", Internet Research, Vol. 25, No. 4, pp. 633-673.

Barnes, S.J. and Mattsson, J. (2016), "Understanding current and future issues in collaborative consumption: A four-stage Delphi study", Technological Forecasting and Social Change, Vol. 104, pp. 200-211.

Belk, R. (2009), "Sharing", Journal of consumer research, Vol. 36, No. 5, pp. 715-734.

Belk, R. (2017), "Sharing without caring", Cambridge Journal of Regions, Economy and Society, Vol. 10, No. 2, pp. 249-261.

Benkler, Y. (2017), "Peer production, the commons, and the future of the firm", Strategic Organization, Vol. 15, No. 2, pp. 264-274.

Botsman, R. and Rogers, R. (2011), What's mine is yours: how collaborative consumption is changing the way we live, Collins, London, UK.

Caillaud, B. and Jullien, B. (2003), "Chicken and egg: Competition among intermediation service providers", RAND Journal of Economics, Vol. 34, No. 2, pp. 309-328.

Claudy, M.C., Garcia, R. and O'Driscoll, A. (2015), "Consumer resistance to innovation-a behavioral reasoning perspective", Journal of the Academy of Marketing Science, Vol. 43, No. 4, pp. 528-544. 
Constantiou, I., Marton, A. and Tuunainen, V.K. (2017), "Four Models of Sharing Economy Platforms.", MIS Quarterly Executive, Vol. 16, No. 4, pp- 231-251.

Corbin, J. and Strauss, A. (2008), Basics of qualitative research, Thousand Oaks, California.

Crossan, M.M. and Apaydin, M. (2010), "A multi-dimensional framework of organizational innovation: A systematic review of the literature", Journal of management studies, Vol. 47, No. 6, pp. 1154-1191.

Davidson, A., Habibi, M.R. and Laroche, M. (2018), "Materialism and the sharing economy: A cross-cultural study of American and Indian consumers", Journal of Business Research, Vol. 82, pp. 364-372.

Eckhardt, G.M. and Bardhi, F. (2015), "The sharing economy isn't about sharing at all", Harvard business review, Vol. 28, No. 1, pp. 2015.

Eisenmann, T.R. (2007), Managing proprietary and shared platforms: A life-cycle view. Division of Research, Harvard Business School, Boston, MA.

Gawer, A. (2014), "Bridging differing perspectives on technological platforms: Toward an integrative framework", Research Policy, Vol. 43, No. 7, pp. 1239-1249.

Gregory, A. and Halff, G. (2017), "Understanding public relations in the 'sharing economy'", Public Relations Review, Vol. 43, No. 1, pp. 4-13.

Guttentag, D.A. and Smith, S.L. (2017), "Assessing Airbnb as a disruptive innovation relative to hotels: Substitution and comparative performance expectations", International Journal of Hospitality Management, Vol. 64, pp. 1-10.

Habibi, M.R., Davidson, A. and Laroche, M. (2017), "What managers should know about the sharing economy", Business Horizons, Vol. 60, No. 1, pp. 113-121.

Hagiu, A. and Wright, J. (2015), "Multi-sided platforms", International Journal of Industrial Organization, Vol. 43, pp. 162-174.

Heylighen, F. (2017), "Towards an Intelligent Network for Matching Offer and Demand: from the sharing economy to the Global Brain", Technological Forecasting and Social Change, Vol. 114, pp. 74-85.

Jansen, H. (2010), "The logic of qualitative survey research and its position in the field of social research methods", Forum Qualitative Sozialforschung/Forum: Qualitative Social Research, Vol. 11, No. 2, pp. 1-20.

Kathan, W., Matzler, K. and Veider, V. (2016), "The sharing economy: Your business model's friend or foe?", Business Horizons, Vol. 59, No. 6, pp. 663-672.

Katz, M.L. and Shapiro, C. (1985), "Network externalities, competition, and compatibility", The American Economic Review, Vol. 75, No. 3, pp. 424-440.

Knox, G. and Eliashberg, J. (2009), "The consumer's rent vs. buy decision in the rentailer", International Journal of Research in Marketing, Vol. 26, No. 2, pp. 125-135. 
Laurell, C. and Sandström, C. (2017), "The sharing economy in social media: Analyzing tensions between market and non-market logics", Technological Forecasting and Social Change, Vol 125, pp. 58-65.

Lee, Z. W. Y., Tommy K.H. Chan, M.S. Balaji, Alain Yee-Loong Chong, (2018) "Why people participate in the sharing economy: an empirical investigation of Uber", Internet Research, Vol. 28 Issue: 3, pp.829-850.

Liñán, F. and Fayolle, A. (2015), "A systematic literature review on entrepreneurial intentions: citation, thematic analyses, and research agenda", International Entrepreneurship and Management Journal, Vol. 11, No. 4, pp. 907-933.

Mair, J. and Reischauer, G. (2017), "Capturing the dynamics of the sharing economy: Institutional research on the plural forms and practices of sharing economy organizations", Technological Forecasting and Social Change, Vol. 125, pp. 11-20.

Milanova, V. and Maas, P. (2017), "Sharing intangibles: Uncovering individual motives for engagement in a sharing service setting", Journal of Business Research, Vol. 75, pp. 159171.

Munoz, P. and Cohen, B. (2017), "Mapping out the sharing economy: A configurational approach to sharing business modeling", Technological Forecasting and Social Change, Vol. 125, pp. 21-37.

Muzellec, L., Ronteau, S. and Lambkin, M. (2015), "Two-sided Internet platforms: A business model lifecycle perspective", Industrial Marketing Management, Vol. 45, pp. 139-150.

Ndubisi, N.O., Ehret, M. and Wirtz, J. (2016), "Relational governance mechanisms and uncertainties in nonownership services", Psychology and Marketing, Vol. 33, No. 4, pp. 250-266.

Parguel, B., Lunardo, R. and Benoit-Moreau, F. (2017), "Sustainability of the sharing economy in question: When second-hand peer-to-peer platforms stimulate indulgent consumption", Technological Forecasting and Social Change, Vol. 125, pp. 48-57.

Piscicelli, L., Ludden, G.D. and Cooper, T. (2018), "What makes a sustainable business model successful? An empirical comparison of two peer-to-peer goods-sharing platforms", Journal of Cleaner Production, Vol. 172, pp. 4580-4591.

Pittaway, L., Robertson, M., Munir, K., Denyer, D. and Neely, A. (2004), "Networking and innovation: a systematic review of the evidence", International Journal of management reviews, Vol. 5, No. 3-4, pp. 137-168.

PwC. (2014). The sharing economy - Sizing the revenue opportunity. Retrieved from http://www.pwc.co.uk/issues/megatrends/collisions/ sharingeconomy/the-sharingeconomy-sizing-the-revenue- opportunity.jhtml

PwC. (2016). Europe's five key sharing economy sectors could deliver $€ 570$ billion by 2025 .Retrieved from https://press.pwc.com/News-releases/europe-s-five-key-sharingeconomy-sectors-could-deliver--570-billion-by-2025/s/45858e92-e1a7-4466-a011a7f6b9bb488f 
Qazi, A., Raj, R.G., Hardaker, G. and Standing, C. (2017), "A systematic literature review on opinion types and sentiment analysis techniques: Tasks and challenges", Internet Research, Vol. 27, No. 3, pp. 608-630.

Ram, S. (1989), "Successful innovation using strategies to reduce consumer resistance: An empirical test", Journal of Product Innovation Management, Vol. 6, No. 1, pp. 20-34.

Randhawa, K., Wilden, R. and Hohberger, J. (2016), "A bibliometric review of open innovation: Setting a research agenda", Journal of Product Innovation Management, Vol. 33, No. 6, pp. 750-772.

Retamal, M. (2017), "Product-service systems in Southeast Asia: Business practices and factors influencing environmental sustainability", Journal of Cleaner Production, Vol. 143, pp. 894-903.

Richard, B. and Cleveland, S. (2016), "The future of hotel chains: Branded marketplaces driven by the sharing economy", Journal of Vacation Marketing, Vol. 22, No. 3, pp. 239248.

Richard, B., Murphy, J. and Altin, L. (2018), "Premium offerings in the sharing economy: Authentic immersions", Journal of Revenue and Pricing Management, Vol. 17, No. 4, pp. 244-255.

Rifkin, J. (2014), The zero marginal cost society: The internet of things, the collaborative commons, and the eclipse of capitalism St. Martin's Press, New York (NY).

Rochet, J. and Tirole, J. (2003), "Platform competition in two-sided markets", Journal of the European Economic Association, Vol. 1, No. 4, pp. 990-1029.

Shapiro, C. and Varian, H.R. (1999), "The art of standards wars", California management review, Vol. 41, No. 2, pp. 8-32.

Statista (2017a). Number of sharing economy users in the United States from 2016 to 2021 (in millions). Retrieved from https://www.statista.com/statistics/289856/numbersharing-economy-users-us/

Statista (2017b). Number of U.S. adults using lodging sharing economy services from 2014 to 2020 (in millions). Retrieved from https://www.statista.com/statistics/292556/numberlodging-sharing-economy-users-us/

Täuscher, K. and Laudien, S.M., 2018. Understanding platform business models: A mixed methods study of marketplaces. European Management Journal, Vol. 36, No. 3, pp.319329.

Trabucchi, D., Buganza, T. and Pellizzoni, E. (2017), "Give away your digital services: leveraging big data to capture value", Research-Technology Management, Vol. 60, No. 2, pp. 43-52.

Trabucchi, D. and Buganza, T., (2019), "Data-driven innovation: switching the perspective on Big Data", European Journal of Innovation Management, Vol. 22, No. 1, pp. 23-40.

Tranfield, D., Denyer, D. and Smart, P. (2003), "Towards a methodology for developing evidence-informed management knowledge by means of systematic review", British Journal of Management, Vol. 14, No. 3, pp. 207-222. 
Trenz, M., Frey, A., and Veit, D. (2018). "Disentangling the facets of sharing: a categorization of what we know and don't know about the Sharing Economy", Internet Research, Vol. 28, No. 4, pp.888-925.

Urbinati, A., Chiaroni, D. and Chiesa, V. (2017), "Towards a new taxonomy of circular economy business models", Journal of Cleaner Production, Vol. 168, pp. 487-498.

Van Eck, N.J. and Waltman, L. (2014), "Visualizing bibliometric networks", in Ding Y., Rousseau R., Wolfram D. (Eds) Measuring Scholarly Impact, Springer, Cham pp, 285-320.

Verganti, R. (2017), Overcrowded: Designing Meaningful Products in a World Awash with Ideas, MIT Press, Boston, MA.

Viswanathan, M., Sridharan, S. and Ritchie, R. (2010), "Understanding consumption and entrepreneurship in subsistence marketplaces", Journal of Business Research, Vol. 63, No. 6, pp. 570-581.

Waltman, L., and N.J. Van Eck. (2013). “A smart local moving algorithm for large-scale modularity-based community detection", The European Physical Journal B, Vol. 86, No. 11, pp. 471-485.

Waltman, L., van Eck, N.J. and Noyons, E.C. (2010), "A unified approach to mapping and clustering of bibliometric networks", Journal of Informetrics, Vol. 4, No. 4, pp. 629-635.

Wang, D. and Nicolau, J.L. (2017), "Price determinants of sharing economy based accommodation rental: A study of listings from 33 cities on Airbnb. com", International Journal of Hospitality Management, Vol. 62, pp. 120-131.

Wilhelms, M., Merfeld, K. and Henkel, S. (2017), "Yours, mine, and ours: A user-centric analysis of opportunities and challenges in peer-to-peer asset sharing", Business Horizons, Vol. 60, No. 6, pp. 771-781.

Williams, C.C., and Horodnic, I.A. (2017), "Regulating the sharing economy to prevent the growth of the informal sector in the hospitality industry", International Journal of Contemporary Hospitality Management, Vol. 29, No. 9, pp. 2261-2278.

Wilson, B. (2017, February 10). What is the 'gig' economy? BBC News. Retrieved from http://www.bbc.com/news/business-38930048

Yang, S., Yang, S., Song, Y., Song, Y., Chen, S., Chen, S., Xia, X. and Xia, X. (2017), "Why are customers loyal in sharing-economy services? A relational benefits perspective", Journal of Services Marketing, Vol. 31, No. 1, pp. 48-62. 